\title{
SBPC/ML: 60 anos
}

Em 31 de maio de 1944 o dr. Erasmo Lima e outros colegas fundavam, no Rio de Janeiro, o que viria a ser a nossa atual Sociedade Brasileira de Patologia Clínica/Medicina Laboratorial. Nesse mês de maio de 2004 comemoramos, portanto, os 60 anos de nossa fundação. Sendo assim, é oportuno nos lembrarmos de alguns dos fatos mais relevantes da nossa história, a qual se confunde com a história do Jornal Brasileiro de Patologia, pois em 1959 sairia o primeiro número da Revista Brasileira de Patologia Clínica, à qual o JBP sucedeu.

Na décadas de 1950 e 1960 a SBPC, já consolidada, viveu uma fase de reconhecimento por entidades internacionais e nacionais como a legítima representante da patologia clínica no Brasil, sendo criado o Título de Especialista em Patologia Clínica, conferido em conjunto com a Associação Médica Brasileira desde 1963. O primeiro congresso brasileiro da especialidade seria realizado, então, em São Paulo, em 1964.

Em 1977, outro grande marco: o lançamento do primeiro programa de ensaios de proficiência do Brasil, que se mantém até hoje e em plena expansão, com a denominação PELM. Com esse programa pioneiro, os laboratórios brasileiros foram instrumentados para a realização dos controles interno e externo, os quais são das maiores ferramentas para a garantia da qualidade das análises laboratoriais de rotina.

Em sintonia com o avanço de toda a sociedade na busca da segurança e da credibilidade da prestação de serviços de saúde, em 1998 foi lançado o Programa de Acreditação de Laboratórios Clínicos (PALC). A SBPC/ML criava, então, um sistema para a melhoria contínua da qualidade dos laboratórios brasileiros, através de requisitos específicos elaborados por especialistas cujo cumprimento é verificado in loco por uma equipe de auditores especialistas.

Lemos no primeiro estatuto da SBPC/ML, entre os seus objetivos: "trabalhar pela elevação de nível das condições científicas e profissionais dos que exercem a especialidade...; estimular a pesquisa original em todos os ramos de trabalho do laboratório clínico...; empreender a publicação de uma revista especializada, onde serão publicados trabalhos científicos de valor...". Não é outra, até hoje, a missão do Jornal Brasileiro de Patologia, agora agregado das sociedades irmãs de patologia e de citopatologia.

O JBP se orgulha de ser parte dessa história. 